\title{
Standardisasi Resume Medis Dalam Pelaksanaan PMK 21/ 2020 Terkait Pertukaran Data Dalam Rekam Medis Elektronik
}

\section{Standardization of Medical Resume in the Implementation of PMK 21/ 2020 Related to Data Exchange In Electronic Medical Records}

\author{
Rano Indradi Sudra \\ Program Studi S1 Manajemen Informasi Kesehatan, Universitas Nasional Karangturi
}

\begin{tabular}{l}
\hline \hline Article Info \\
\hline Article history: \\
Received Jan 22, 2021 \\
Revised Feb 15, 2021 \\
Accepted Feb 23, 2021 \\
\hline
\end{tabular}

\section{Keywords:}

Standardization Medical Summary Electronic Medical Record Health Information Exchange

\begin{abstract}
ABSTRAK
The issuance of Regulation of the Minister of Health number 21 of 2020 concerning the Strategic Plan of the Ministry of Health year 2020-2024 encourages the need for appropriate implementation measures. One of the things that was proclaimed to be realized in 2024 is the application of integrated electronic medical records (RME) reached $100 \%$. This is intended to be able to support the exchange of medical resume data between hospitals (health information exchange/HIE). To implement this HIE requires standardization and regulation that regulates it. This research is qualitative, using a sosiolegal approach that focuses on the depth of material related to documenting standards in medical resumes enriched with literature studies. Regulations related to medical resumes/discharge summaries that exist at this time have not set about language standards, abbreviations, symbols, and units for documenting in medical resumes. The existing regulations also have not explained the dictionary related matters.
\end{abstract}

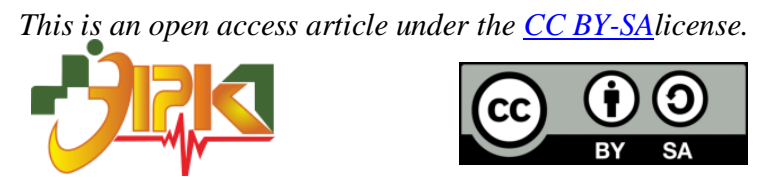

\section{Corresponding Author:}

Rano Indradi Sudra,

Program Studi S1 Manajemen Informasi Kesehatan (MIK)

Universitas Nasional Karangturi,

Jl. Raden Patah 182-192 Semarang

Email: rano.indradi@gmail.com

\section{PENDAHULUAN}

Dalam Undang-Undang Nomor 17 Tahun 2007 tentang Rencana Pembangunan Jangka Panjang Nasional Tahun 2005-2025 disebutkan bahwa pada hakekatnya pembangunan kesehatan merupakan upaya yang seharusnya dilakukan oleh seluruh komponen bangsa Indonesia. Pembangunan kesehatan bertujuan untuk meningkatkan kesadaran, kemauan, dan kemampuan hidup sehat untuk setiap orang supaya tercapai tingkat kesehatan masyarakat yang setinggi-tingginya. Kondisi ini akan menjadi investasi untuk pembangunan sumber daya manusia yang produktif baik secara sosial maupun ekonomi (Undang-Undang nomor 17 Tahun 2007 Tentang Rencana Pembangunan Jangka Panjang Nasional Tahun 2005-2025, 2007). 
Setiap layanan kesehatan wajib didokumentasikan dalam bentuk rekam medis. Isi rekam medis meliputi data non medis dan medis. Data non medis misalnya data terkait demografi pasien, sedangkan data medis dapat meliputi hasil anamnesis, hasil pemeriksaan fisik, hasil pemeriksaan penunjang, tindakan medis yang telah dilakuakan, terapi, dan diagnosis (Kemenkes, 2008).

Mengingat fungsi rekam medis yang dapat digunakan untuk mengidentifikasi pasien, menunjang penentuan diagnosis atau menyatakan alasan utama pasien datang ke tempat pelayanan kesehatan, mengesahkan alasan pemberian tindakan dan mendokumentasikan semua hasilnya secara akurat, maka sebagaimana tercantum dalam Medical Record Manual dari World Health Organization (WHO), rekam medis harus berisi data yang cukup untuk menunjang berbagai keperluan tersebut (World Health Organization, 2006).

Kewajiban untuk membuat rekam medis diamanatkan oleh Undang-undang no.44 tahun 2009 tentang Rumah Sakit pada bab VIII pasal 29 ayat 1 (h). Dalam bagian penjelasannya tercantum bahwa penyelenggaraan rekam medis sebagaimana dimaksud dalam ayat ini adalah penyelenggaraan rekam medis yang sesuai dengan standar yang berlaku dan standar ini secara bertahap akan diupayakan meningkat untuk mencapai standar internasional" (Undang-undang nomor 44 tahun 2009 Tentang Rumah Sakit, 2009).

Dalam Standar Nasional Akreditasi Rumah Sakit (SNARS) edisi 1.1 tahun 2019 yang diterbitkan oleh Komisi Akreditasi Rumah Sakit (KARS) disebutkan bahwa rekam medis adalah bukti tertulis (baik berbasis kertas maupun elektronik) yang digunakan untuk merekam semua informasi hasil layanan kesehatan kepada pasien. Hal ini meliputi (namun tidak terbatas pada) temuan hasil asesmen, rencana asuhan yang akan diberikan, rincian pelaksanaan asuhan dan pengobatan, catatan perkembangan pasien terintegrasi (CPPT), serta ringkasan pasien saat pulang (discharge summary). Dalam standard ini juga disebutkan bahwa rekam medis bisa dibuat secara elektronik sebagaimana disebutkan juga dalam Permenkes 269/ 2008 tentang Rekam Medis (Kemenkes, 2008); (KARS, 2019).

Pemanfaatan rekam medis elektronik (RME) diharapkan dapat meningkatkan dan memperkuat manfaat rekam medis. Pemanfaatan RME terutama adalah untuk kepentingan pelayanan terhadap pasien, meliputi pelayanan klinik (medis) maupun administratif. Informasi yang dihasilkan dari RME juga bermanfaat untuk pendidikan, penyusunan regulasi, penelitian, pengelolaan kesehatan komunitas, penunjang kebijakan, dan untuk menunjang layanan kesehatan rujukan (Sudra, 2020).

E-kesehatan nasional yang telah disusun pemerintah merupakan suatu konsep menyeluruh untuk meliputi perencanaan, pengembangan, implementasi, serta evaluasi dalam pemanfaatan teknologi informasi dan komunikasi (TIK) di bidang kesehatan secara nasional. Dalam e-kesehatan, teknologi informasi dan komunikasi didayagunakan utamanya untuk meningkatan kualitas pelayanan kesehatan dan proses kerja yang efisien dan efektif. Secara umum, e-kesehatan meliputi health informatics (informatika kesehatan) dan tele-health (upaya kesehatan jarak jauh). Visi dari e-kesehatan yaitu meningkatkan aksesibilitas dan kesinambungan layanan kesehatan bagi seluruh rakyat Indonesia secara berkualitas. Salah satu penerapan e-kesehatan adalah RME. Hingga saat ini belum ada regulasi yang secara khusus dan komprehensif mengatur tentang RME. Beberapa pasal di beberapa regulasi yang terkait dengan RME juga ada yang berpotensi tidak sinkron. Mengingat pesatnya perkembangan dan luasnya potensi implementasi teknologi informasi dalam layanan kesehatan, diperlukan adanya harmonisasi dan rekonstruksi regulasi untuk mengatur RME. Dalam konsep e-kesehatan, pelepasan informasi (release of information) dan pertukaran informasi kesehatan (health information exchange) merupakan suatu keniscayaan. Agar sistem dapat saling berkomunikasi maka diperlukan standardisasi dalam berbagai aspek mulai dari input, proses, hingga outputnya (Kemenkes, 2017). 
Periode tahun 2020-2024 merupakan bagian dan tahapan akhir dari Rencana Pembangunan Jangka Panjang Nasional (RPJPN) 2005-2025. Periode ini sekaligus juga merupakan periode pembangunan jangka menengah yang strategis dan penting. Periode RPJMN 2020-2024 akan memengaruhi pencapaian target pembangunan dalam RPJPN, yang mana pada periode tersebut pendapatan perkapita Indonesia ditargetkan akan mencapai tingkat kesejahteraan yang setara dengan negara-negara berpenghasilan menengah atas (Upper-Middle Income Country). Kondisi ini akan mendorong terbentuknya infrastruktur, kualitas sumber daya manusia, pelayanan publik, serta kesejahteraan rakyat yang lebih baik.

Pemanfaatan teknologi informasi dibidang kesehatan cukup luas. Pemanfaatan ini antara lain mendukung perencanaan kesehatan melalui e-planning, e-budgeting dan emonev. Dalam hal penyediaan data kesehatan, sistem yang dikembangkan juga sudah beragam, seperti SITT (Sistem Informasi Tuberkulosis Terpadu), KOMDAT (Komunikasi Data), SIHA (Sistem Informasi HIV/AIDS), e-Sismal (Sistem Informasi Surveilans Malaria), dan sistem PIS-PIK (Program Indonesia Sehat dengan Pendekatan Keluarga). Integrasi sistem data sudah selayaknya dilakukan untuk menghasilkan data yang reliable dan valid. Demikian juga dengan integrasi data SIK (Sistem Informasi Kesehatan) dengan data JKN serta pemanfaatan data Pelayanan BPJS Kesehatan.

Pengembangan SISRUTE (Sistem Rujukan Terintegrasi) bertujuan untuk meningkatkan sistem rujukan antara Fasilitas Kesehatan Tingkat Pertama (FKTP) dan Fasilitas Kesehatan Rujukan Tingkat Lanjutan (FKRTL). Pengembangan sistem rekam medis elektronik (RME) yang mendukung pertukaran data resume medis pasien antar rumah sakit (smart care) (Kemenkes, 2020).

\section{METODE PENELITIAN}

Jenis/tipe penelitian dalam penelitian ini adalah kualitatif. Penelitian berfokus pada kedalaman materi yang berkaitan dengan standard pendokumentasian dalam resume medis rekam medis elektronik (RME) didukung dengan kajian literatur untuk merumuskan konten regulasi yang jelas dan harmonis terkait standard pendokumentasian dalam resume medis RME.

Penelitian ini menggunakan pendekatan sosiolegal, yaitu penelitian hukum non doktrinal yang mengkaji hukum dengan memadukan ilmu hukum dan ilmu sosial. Pendekatan terkait ilmu hukum dipergunakan untuk telaah tekstual serta pasal-pasal yang ada dalam regulasi yang diteliti. Pendekatan terkait ilmu sosial dipergunakan untuk mengkaji aspek-aspek sosial non hukum (eksternal) yang ikut berpengaruh terhadap bekerjanya hukum dalam batas konteks yang diteliti.

Penelitian ini menggunakan paradigma konstruktivisme, yaitu merekonstruksi regulasi terkait standard pendokumentasian dalam resume medis RME agar sesuai dengan tujuan pengembangan RME sebagaimana tercantum dalam Permenkes nomor 21 tahun 2020.

\section{HASIL DAN PEMBAHASAN}

Rekam medis elektronik (RME) menempati posisi penting dari konsep sistem informasi kesehatan dan e-kesehatan. Mengingat hal ini, dibutuhkan keseriusan untuk merancang dan mengaplikasikan RME. Institute of Medicine (IOM) tahun 2003 merumuskan RME sebagai suatu sistem yang memiliki unsur-unsur sebagai berikut:

- Pengumpulan informasi kesehatan berkelanjutan berbasis elektronik tentang seorang pasien;

- Siap setiap saat, dapat segera menampilkan informasi berbasis elektronik, baik pada tingkat personal maupun tingkat populasi, oleh pihak yang berwenang;

- Sesuai/relevan dengan kebutuhan pengetahuan dan sistem pendukung keputusan yang meningkatkan kualitas, keamanan, dan efisiensi dari pelayanan pasien; 
- Mendukung efisiensi proses pelayanan kesehatan.

Suatu sistem RME mencakup lingkup sejak dari perekamam data (capturing), penyimpanan data (storing), pengolahan data (processing), penjagaan aspek keamanan informasi (privacy \& security), komunikasi dan penyajian data (Release of Information / RoI), hingga ke pemusnahan data pada kondisi yang dibutuhkan (destructing).

Konten dari RME telah dirumuskan oleh Health Information Management Systems Society's (HIMSS) tahun 2006, meliputi antara lain: data demografi pasien, catatan perkembangan kondisi pasien, masalah-masalah yang timbul, obat dan terapi lain yang diberikan, tanda-tanda vital (suhu, nadi napas, dan sebagainya), riwayat kesehatan pada masa yang lalu, riwayat imunisasi, hasil pemeriksaan laboratorium, hasil pemeriksaan radiologi, hasil konsultasi, data penunjang lain yang berkaitan (HIMSS, 2003).

Penggunaan RME diharapkan bisa menghasilkan pencatatan rekam medis yang lengkap untuk menunjang kebutuhan aktifitas pelayanan dan manajemen pelayanan serta mampu menghasilkan informasi dan laporan yang sesuai dengan kebutuhan. Bahwa rekam medis bisa dibuat berbasis elektronik telah disebutkan dalam Permenkes nomor 269 tahun 2008 tentang Rekam Medis pasal 2 ayat (1). Terkait hal ini, penandatanganan dalam rekam medis elektronik bisa menggunakan metode personal identification number (PIN) atau nomor identitas pribadi sebagaimana disebutkan di bagian penjelasan pasal 46 ayat (3) Undang-Undang nomor 29 tahun 2004 tentang Praktek Kedokteran. Lebih jauh ditegaskan dalam pasal 14 Peraturan Pemerintah nomor 46/2014 tentang Sistem Informasi Kesehatan (SIK) yang menyebutkan bahwa rekam medis elektronik dan nonelektronik merupakan sumber dari data dan informasi kesehatan dari fasilitas pelayanan kesehatan. Selain sebagai sumber data dan informasi, dalam pasal 17 poin b dari regulasi ini disebutkan pula bahwa penyelenggaraan rekam medik bisa meliputi rekam medik berbasis elektronik dan rekam medik kertas atau nonelektronik.

Dalam pasal 3 ayat (1) Permenkes nomor 82/2013 tentang Sistem Informasi Manajemen Rumah Sakit (SIMRS) disebutkan bahwa "Setiap Rumah Sakit wajib menyelenggarakan SIMRS". Bagian lampiran dari regulasi ini menyebutkan rekam medis menjadi salah satu variabel dalam SIMRS. Pengertian dari SIMRS menurut pasal 1 dalam regulasi ini adalah, pengertian dari SIMRS yang merupakan bagian dari Sistem Informasi Kesehatan. Sistem Informasi Kesehatan itu sendiri memadukan beragam sumber daya data dan informasi untuk menunjang kebutuhan berbagai keputusan dalam pembangunan kesehatan (Kemenkes, 2013).

Dalam pasal 1 Undang-Undang nomor 19/2016 tentang Perubahan Atas UU nomor 11/2008 tentang Informasi dan Transaksi Elektronik (ITE) disebutkan tentang batasan dokumen elektronik yang berdasarkan ini maka dokumentasi hasil layanan kesehatan (rekam medis) yang disimpan dalam bentuk elektronik (RME) memenuhi kriteria sebagai dokumen elektronik.

Pasal 3 ayat (2) dalam Permenkes nomor 269/2008 tentang Rekam Medis menyebutkan adanya ringkasan pulang (discharge summary). Ringkasan pulang (atau disebut juga resume medis) merupakan lembar yang berisi item-item data yang signifikan terkait diagnosis utama pasien, meliputi kondisi sejak pasien masuk perawatan hingga pasien keluar/pulang. Pasal 4 ayat (2) dalam regulasi ini menyatakan bahwa: Isi ringkasan pulang sebagaimana dimaksud pada ayat (1) sekurang-kurangnya memuat:

a. identitas pasien;

b. diagnosis masuk dan indikasi pasien dirawat;

c. ringkasan hasil pemeriksaan fisik dan penunjang, diagnosis akhir, pengobatan dan tindak lanjut; dan

d. nama dan tanda tangan dokter atau dokter gigi yang memberikan pelayanan kesehatan. 
Berbeda dengan lembar rekam medis lainnya yang disimpan minimal 5 tahun, menurut pasal 8 ayat (3) dalam regulasi ini, ringkasan pulang disimpan selama 10 tahun terhitung sejak tanggal pembuatannya. Standard Nasional Akreditasi Rumah Sakit (SNARS) edisi 1.1 yang disusun dan mulai dipergunakan oleh Komisi Akreditas Rumah Sakit sejak 1 Januari 2020 dalam standard 15 tentang Manajemen Informasi dan Rekam Medis (MIRM) menyebutkan bahwa: ringkasan pasien pulang memuat :

- riwayat kesehatan yang lalu, hasil pemeriksaan fisik dan pemeriksaan diagnostik.

- data penunjang indikasi pasien dirawat inap, diagnosis, dan komorbiditas lain.

- prosedur terapi dan tindakan yang telah dilaksanakan.

- obat yang telah diberikan selama pelayanan, termasuk juga obat yang dilanjutkan penggunaannya setelah pasien keluar RS.

- kondisi kesehatan pasien (status present) saat pasien akan pulang/keluar RS.

- instruksi tindak lanjut.

- dijelaskan kepada pasien/ keluarga dan ditandatangani oleh pasien/keluarga (KARS, 2019).

Rencana strategis kementerian kesehatan tahun 2020-2024 sebagaimana tertuang dalam Permenkes nomor 21/2020 menyatakan bahwa pengaplikasian Sistem Rujukan Terintegrasi (SISRUTE) merupakan bagian dari sistem informasi penyelenggaraan pelayanan kesehatan terpadu berbasis IT yang bertujuan meningkatkan sistem rujukan antara FKTP dan FKRTL. Sistem rekam medis elektronik yang akan dikembangkan adalah sistem dapat mendukung pertukaran data resume medis pasien antar rumah sakit (smart care). Pada periode 2020-2024 ini, pengembangan dan pemantapan Sistem Informasi Kesehatanditujukan untuk menghasilkan layanan informasi kesehatan yang lebih cepat, valid, mendukung resource sharing; dan berbasis elektronik terintegrasi (Kemenkes, 2020).

Regulasi-regulasi terkait resume medis/ringkasan keluar (discharge summary) tersebut diatas belum mengatur tentang standard bahasa, singkatan, simbol, dan satuan untuk pendokumentasian dalam resume medis. Regulasi yang ada tersebut juga belum menjelaskan hal terkait kamus data (data dictionary) untuk masing-masing item data dalam resume medis, utamanya resume medis berbasis elektronik. Hal ini penting untuk menunjang fungsi dan pemanfaatan resume medis dalam RME sebagai sumber data dalam health information exchange.

Mengingat posisi RME sebagai pintu masuk data dalam konsep e-kesehatan yang mana dimungkinkan terjadi health information exchange (HIE) maka keberadaan standard pendokumentasian dan data dictionary ini mutlak dibutuhkan. Standard ini akan membentuk kesamaan langkah dalam pendokumentasian dan keseragaman pengertian dalam penggunaan informasi berbasis RME. Dengan demikian tidak terjadi perbedaan interpretasi makna karena keberagaman bahasa, singkatan, simbol, dan/atau satuan yang digunakan dalam pendokumentasian. Penentuan item-item dalam resume medis juga akan menjamin kecukupan informasi saat resume medis tersebut digunakan untuk berbagai kebutuhan, misalnya untuk menunjang SISRUTE.

\section{KESIMPULAN}

Regulasi-regulasi terkait resume medis, baik manual maupun elektronik, yang berlaku saat ini, belum mengakomodir standardisasi pendokumentasian dalam resume medis, utamanya dalam rekam medis elektronik. Standarisasi yang dibutuhkan meliputi (namun tidak terbatas pada) standard konten (item-item yang tercantum), standard peristilahan (terminologi); singkatan; simbol; satuan, dan standard data dictionary.

Perlu dilakukan penelitian yang lebih teknis dan mendalam terkait standardisasi pendokumentasian dalam resume medis rekam medis elektronik terkait rencana 
penggunaannya sesuai rencana strategis kementerian kesehatan tahun 2020-2024 sebagaimana tertuang dalam Permenkes nomor 21/2020.

\section{REFERENCES}

HIMSS. (2003). Electronic Health Record Definition Model Version 1.1.

KARS. (2019). Standar Nasional Akreditasi Rumah Sakit (SNARS) edisi 1.1. Jakarta: KARS.

Kemenkes. (2008). Peraturan Menteri Kesehatan RI nomor 269/MENKES/PER/III/2008 Tentang Rekam Medis. Rekam Medis.

Kemenkes. (2013). Peraturan Menteri Kesehatan nomor 82 tahun 2013 Tentang Sistem Informasi Manajemen Rumah Sakit.

Kemenkes. (2017). Peraturan Menteri Kesehatan nomor 46 tahun 2017 tentang Strategi eKesehatan Nasional.

Kemenkes. (2020). Peraturan Menteri Kesehatan nomor 21 tahun 2020 Tentang Rencana Strategis Kementerian Kesehatan 2020-2024.

Peraturan Pemerintah nomor 46 tahun 2014 Tentang Sistem Informasi Kesehatan. (2014).

Sudra, R. (2020). Rekam Medis - edisi 3 (3 ed.). Tangerang Selatan: Universitas Terbuka.

Undang-Undang nomor 17 Tahun 2007 Tentang Rencana Pembangunan Jangka Panjang Nasional Tahun 2005-2025. (2007).

Undang-undang nomor 19 tahun 2016 tentang Perubahan atas Undang-undang nomor 11 tahun 2008 tentang ITE. (2016).

Undang-Undang nomor 29 Tahun 2004 Tentang Praktik Kedokteran. (2004).

Undang-undang nomor 44 tahun 2009 Tentang Rumah Sakit. (2009).

World Health Organization. (2006). Medical Record Manual - a Guide for Developing Countries.

\section{BIOGRAPHIES OF AUTHORS}

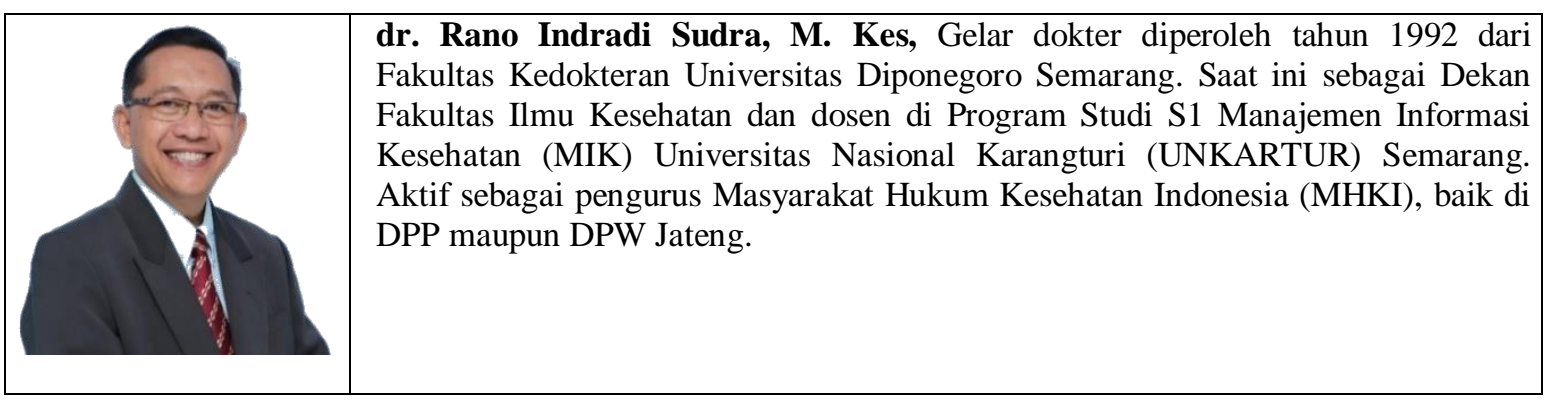

